\title{
DESENVOLVIMENTO DE UM AMBIENTE COMPUTACIONAL PARA SIMULAÇÃO DINÂMICA DE VEÍCULOS
}

\author{
Felipe Luiz Lorenzi, Rogério José Marczak, Fábio Bazacas Zetola, Daiane Pioli \\ UFRGS - Universidade Federal do Rio Grande do Sul \\ E-mails: felipellorenzi@gmail.com,rato@mecanica.ufrgs.br, fabio_bazacas@ hotmail.com, \\ daiapioli@gmail.com
}

\begin{abstract}
RESUMO
O presente trabalho apresenta o desenvolvimento de uma plataforma computacional para a criação e testes de circuitos de teste, utilizados na análise dinâmica de veículos. A plataforma é baseada na implementação de uma interface gráfica, a qual se comunica com um programa de simulação e outro de geração de pavimentos, tornando o processo interativo. O programa armazena cada trecho do circuito como uma função paramétrica, possibilitando que a ele seja associado um perfil de terreno específico, tornando possível a criação de diferentes perfis de excitação para o modelo de veículo ou circuito a ser estudado. Assim, torna-se possível desenvolver uma pista de testes com diversas geometrias, associando a cada trecho da pista diferentes tipos de terreno e agressividades e testar seus efeitos sobre um dado veículo.
\end{abstract}

\section{INTRODUÇÃO}

O surgimento e aprimoramento de ferramentas de simulação numérica possibilitou o desenvolvimento de produtos mais eficientes. A competitividade existente no mercado atual exige, cada vez mais, maiores investimentos dos fabricantes em pesquisa e desenvolvimento de produto, de modo que seja possível entregar ao consumidor final um produto mais complexo e, ao mesmo tempo, de baixo custo.

Em tempos aonde a sustentabilidade é o foco principal no lançamento de um novo produto, aumentou-se ainda mais a concorrência no mercado automotivo, ocasionada pela busca por veículos mais eficientes e por processos produtivos menos prejudiciais ao meio ambiente.

O projeto de estruturas veiculares envolve o levantamento numérico do histórico de diversos carregamentos e esforços, necessários para a prevenção de falhas por fadiga dos componentes. A criação de circuitos de testes juntamente com instrumentação de veículos é um procedimento comum na indústria, uma vez que permite atualizar os modelos numéricos com resultados experimentais e calibrá-los para incrementar sua confiabilidade. Por outro lado, procedimentos experimentais são extremamente caros, devido à quantidade e os custos dos equipamentos envolvidos no processo.

Uma vez calibrados, os programas de simulação podem ser empregados para avaliar o desempenho de veículos em uma variada gama de situações, sem incorrer em maiores custos experimentais. A necessidade de um software computacional que simule o comportamento de 
um veículo em circuitos diversos e com condições de terreno diversas surge, então, de modo a diminuir o tempo e, principalmente, os custos envolvidos no projeto de veículos.

O algoritmo desenvolvido objetiva permitir ao analista criar circuitos de testes, associar perfis de terrenos e velocidades a cada um dos trechos do circuito, e resolver as equações dinâmicas que governam o comportamento do veículo em tráfego. O principal resultado obtido são os históricos de forças atuando na estrutura do veículo, bem como deslocamentos e rotações do mesmo.

\section{INFORMAÇÕES GERAIS}

O desenvolvimento da interface gráfica foi feito utilizando o software comercial Matlab®. A plataforma desenvolvida se comunica com um programa para geração de terrenos, também desenvolvido utilizando este software, e com um programa para a simulação dinâmica do estudo.

A interface gráfica foi desenvolvida buscando a agilidade na criação do circuito e a facilidade na determinação e configuração dos parâmetros da simulação. Por isso, optou-se pela divisão do estudo em abas, guardando para cada aba uma etapa específica da configuração da simulação. Para isso, foram criadas quatro abas contendo as etapas da configuração do estudo, nomeadas da seguinte forma: "Edição", "Seleção de Terreno", "Perfis de Velocidades" e "Veículo". Uma quinta aba, nomeada "Simulação", foi criada para a visualização dos resultados.

\section{EDIÇÃO}

A primeira aba é utilizada para criar, editar ou importar uma pista de testes. A criação de um circuito de testes se dá pela adição de retas, curvas à direita ou curvas à esquerda através dos botões assim nomeados e pela configuração dos trechos na tabela posicionada abaixo dos mesmos, conforme demonstrado na Figura 1.

Para retas, apenas é necessário informar a extensão da mesma. Já para curvas, além da extensão, faz-se necessário a entrada do raio de curvatura. Para os três tipos de trecho citados, o usuário pode informar a variação de elevação, bem como a inclinação lateral no início e no final do trecho. Por convenção, o primeiro trecho do circuito a ser criado é uma reta, com ponto inicial na origem do sistema de coordenadas e coeficiente angular zero, o qual pode ser editado pelo usuário nas configurações do programa.

$\mathrm{Na}$ janela de Edição, também poder ser visualizadas algumas informações importantes a respeito do circuito, como elevação, número de curvas, extensão da maior reta, etc. 


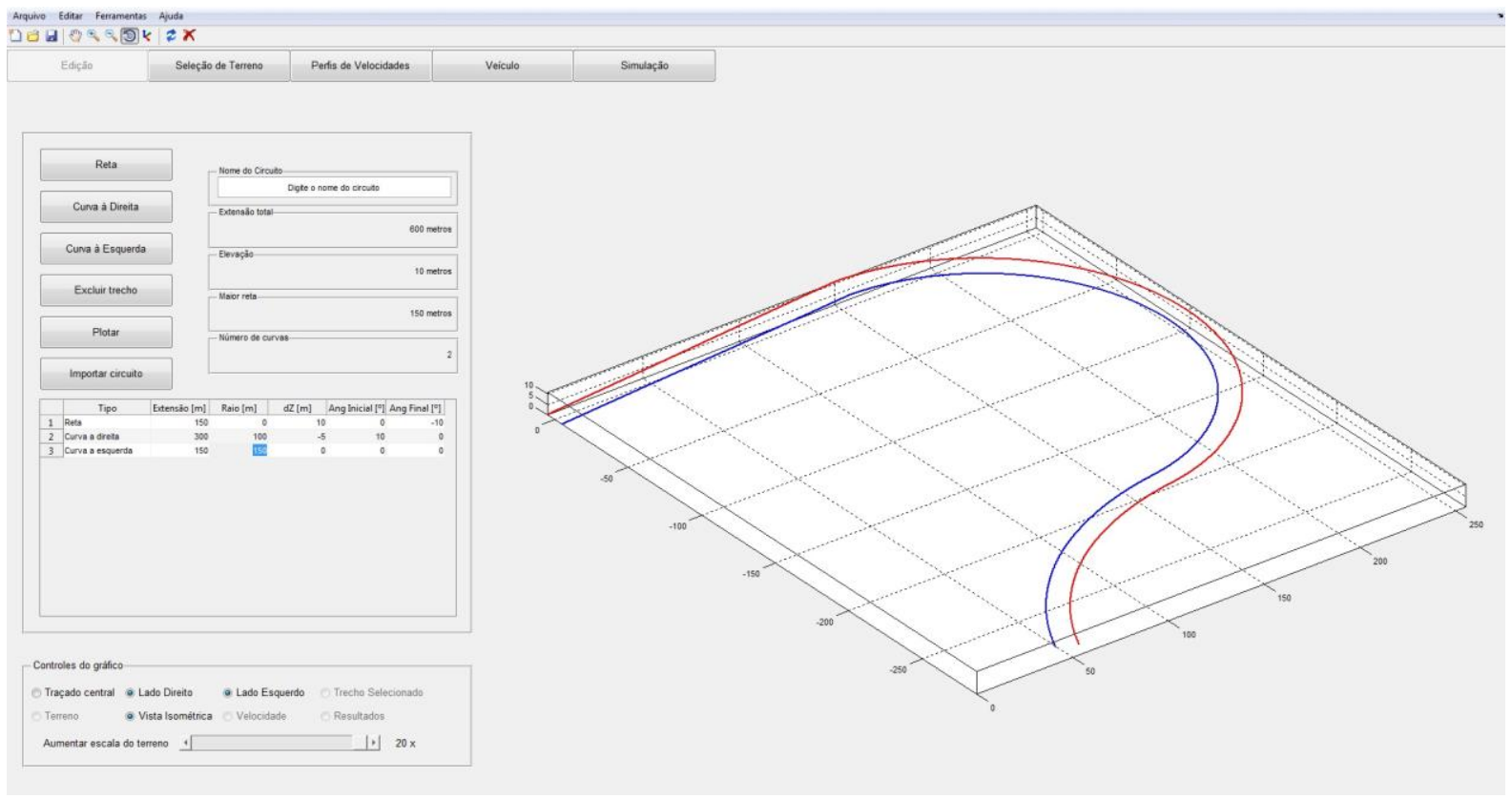

Figura 1. Janela de edição e criação dos circuitos de testes

O programa calcula automaticamente a orientação dos trechos subsequentes criados. Se o trecho subsequente for uma reta, são avaliados os dois últimos pontos do trecho antecedente, de modo a encontrar o coeficiente angular da reta que liga estes dois pontos, atribuindo este mesmo coeficiente a próxima reta criada. Os mesmos pontos são avaliados quando o trecho subsequente for uma curva. Porém, a reta que liga os dois últimos pontos do trecho anterior é utilizada para encontrar o centro de curvatura da curva, uma vez que esta reta deve ser perpendicular à reta que liga o centro de curvatura ao ultimo ponto do trecho anterior, mantendo a curva tangente ao trecho que a antecede. A Figura 2 mostra o Circuito de Monza, criado utilizando o programa.

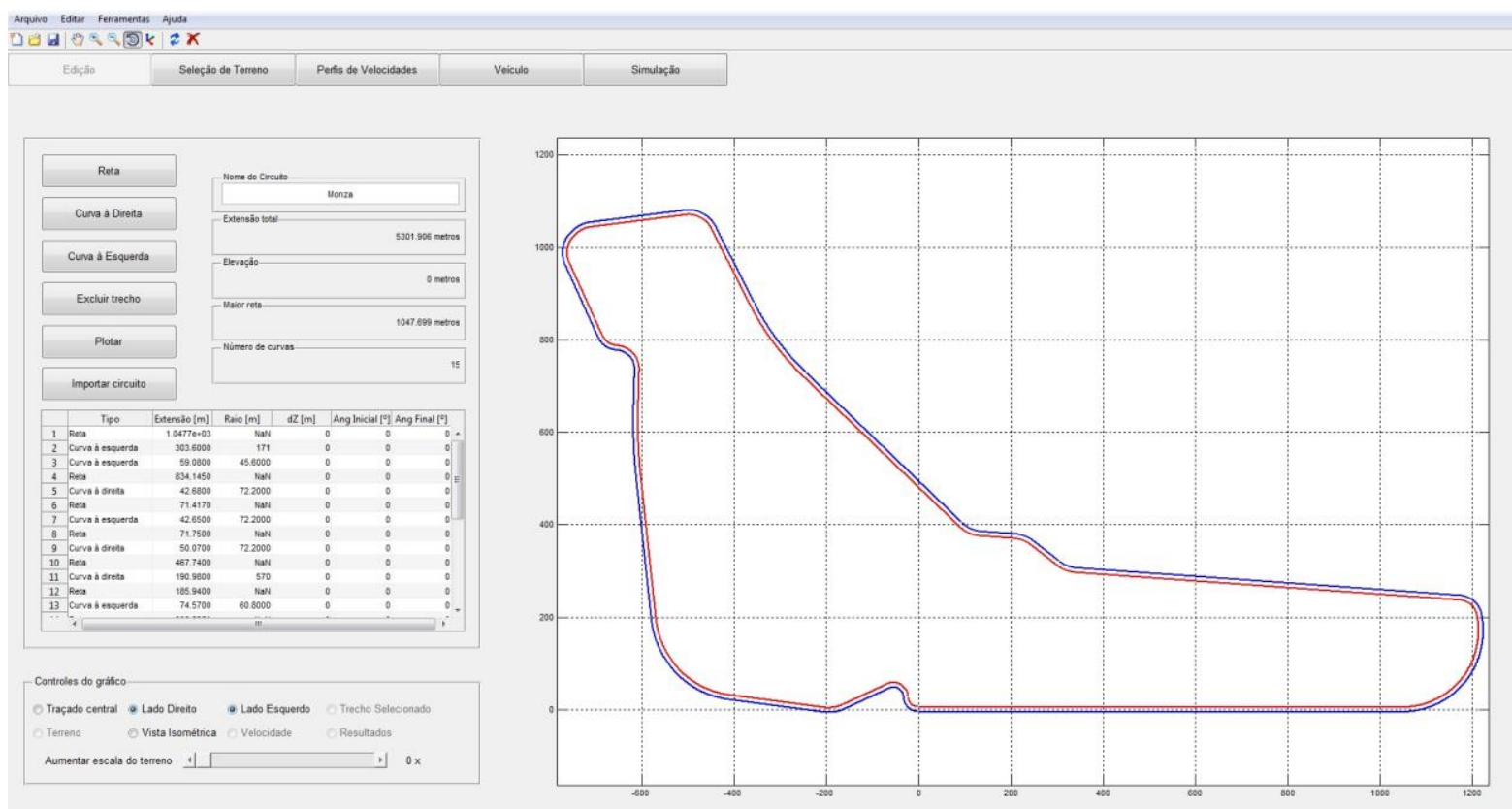

Figura 2. Circuito de Monza criado no programa 


\section{SELEÇÃO DE TERRENO}

Na aba Seleção de Terreno, o usuário pode atribuir um perfil de terreno específico para cada trecho do circuito, ou um mesmo perfil para todos os trechos. O perfil de terreno utilizado pode ser gerado através do programa para geração de pavimentos McProfile, ou pode ser gerado pelo próprio usuário através de um arquivo de texto. O terreno escolhido é demonstrado no gráfico da parte inferior do painel, conforme a Figura 3. Cada perfil de terreno é adicionado como um ganho ao circuito criado pelo usuário, sendo, assim, facilmente editável. A Figura 4 mostra a janela de gráficos do programa McProfile, utilizada na geração dos terrenos.

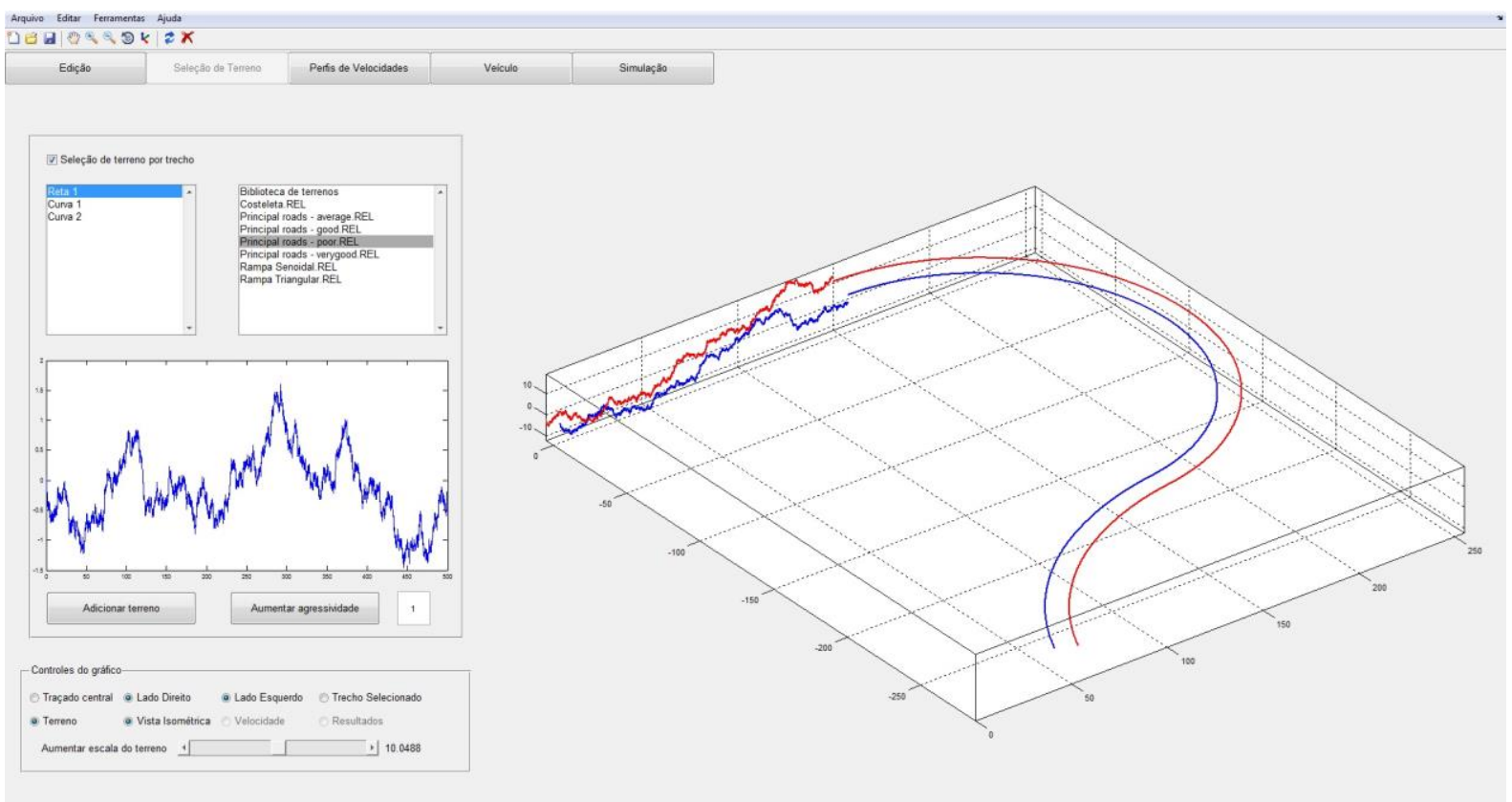

Figura 3. Janela de Seleção de Terreno demonstrando o perfil de terreno selecionado para o primeiro trecho do circuito.
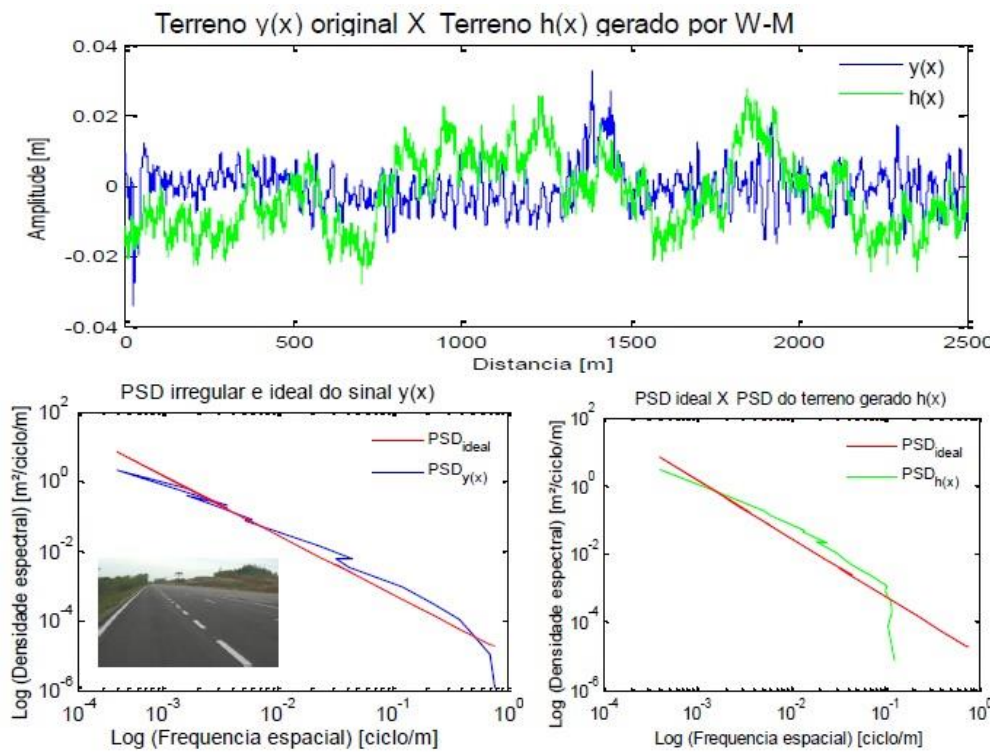

Figura 4. Janela de gráficos do programa McProfile, utilizado para a criação dos terrenos. Imagem cedida pelo autor. 


\section{PERFIS DE VELOCIDADES}

A aba Perfis de Velocidades é utilizada para determinar a variação da velocidade do veículo no circuito. $\mathrm{O}$ usuário pode estabelecer uma velocidade constante para todo o circuito, ou determinar como a velocidade varia em cada um dos trechos criados. Neste caso, o usuário pode dividir cada trecho em seções e informar a velocidade inicial e final em cada uma das seções. O perfil de velocidade é mostrado no gráfico na parte inferior do painel, conforme a Figura 5.

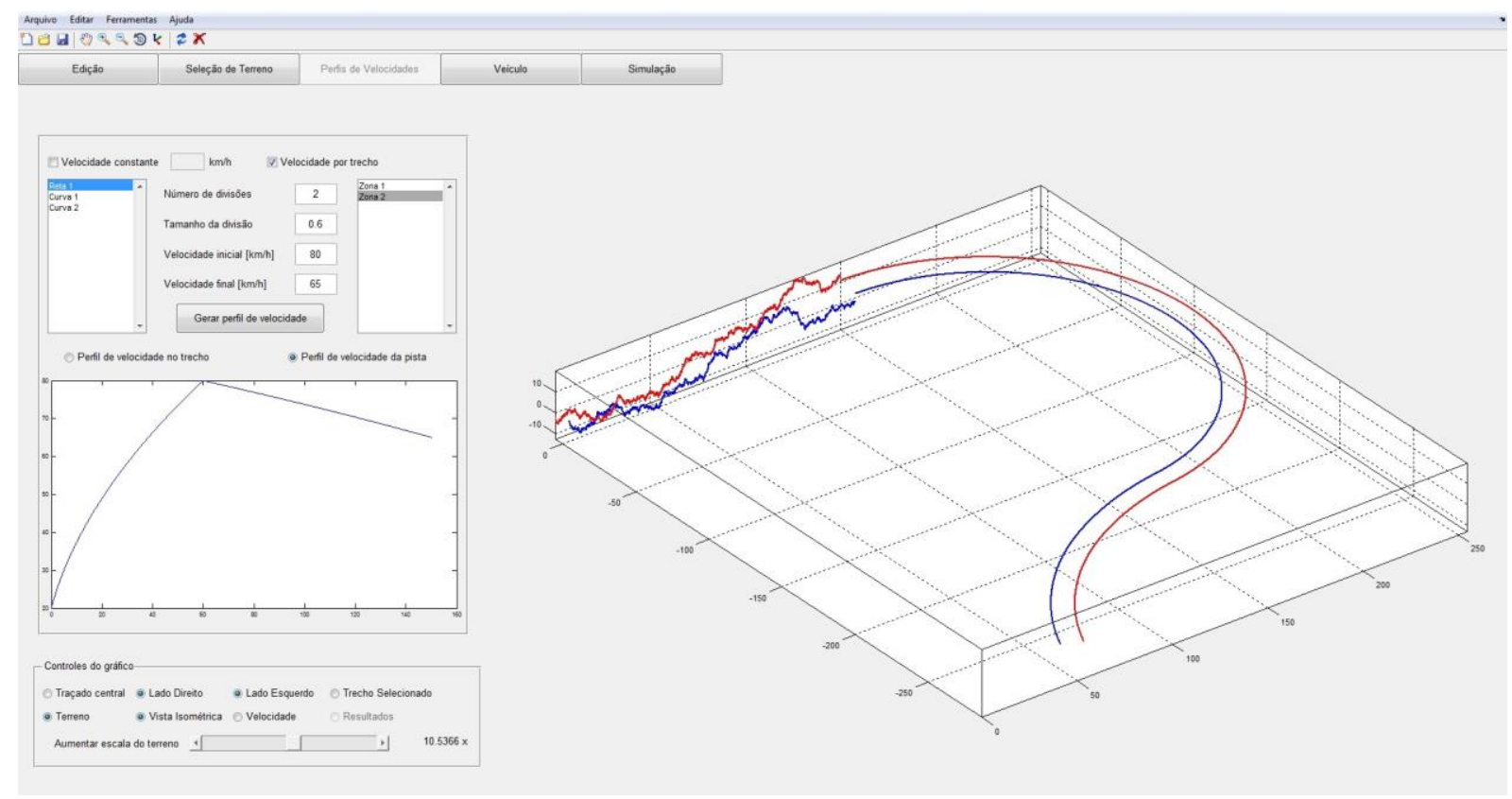

Figura 5. Janela de criação dos Perfis de Velocidade do circuito

\section{VEÍCULO}

A quarta aba do programa é utilizada para configurar o veículo alvo do estudo. Existem três configurações de veículos possíveis disponíveis, que diferem pela quantidade de eixos e tipo de suspensão utilizada em cada um dos eixos. São eles: veículo com dois eixos e suspensão independente nas quatro rodas; veículo com dois eixos, suspensão independente na dianteira e eixo rígido na traseira; veículo com três eixos com suspensão independente no eixo dianteiro e eixo rígido nos dois eixos traseiros.

O tipo de veículo é selecionado da biblioteca e suas informações são demonstradas no painel. O usuário pode, rapidamente, editar a rigidez das molas, coeficientes de amortecimento, massas, posição dos eixos, e etc., e verificar a influência de cada um destes fatores no comportamento dinâmico do veículo. A Figura 6 demonstra a aparência da janela de edição do veículo. 


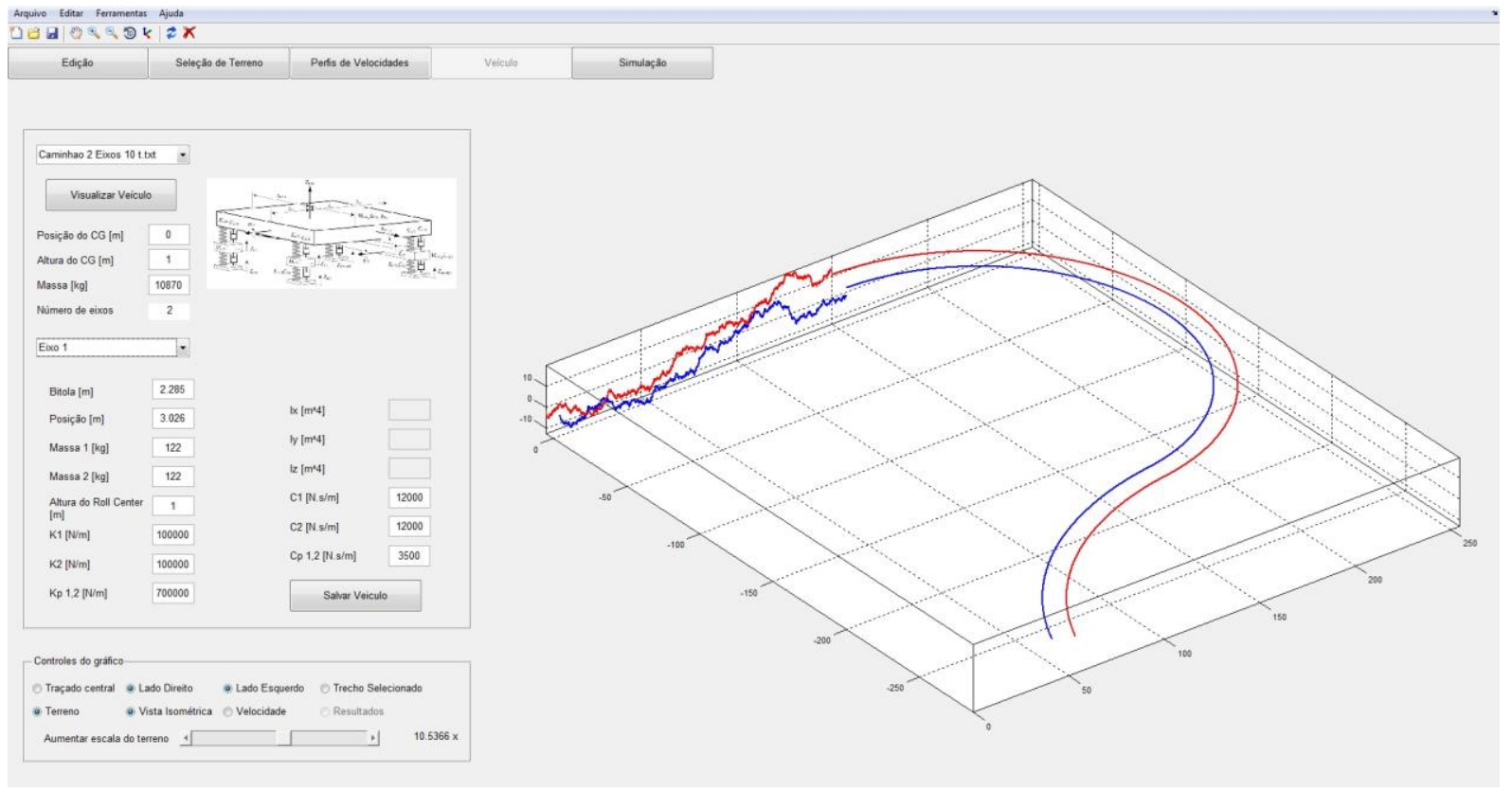

Figura 6. Janela de edição do veículo, demonstrado um veículo de dois eixos com suspensão independente na dianteira e eixo rígido na traseira sendo editado.

\section{SIMULAÇÃO}

A última aba do programa é utilizada para iniciar a simulação e na visualização dos resultados. Nela, o usuário escolhe o trecho e as variáveis que deseja analisar, e os resultados são exibidos na tela, conforme mostrado na Figura 7. Como saída do programa, o usuário pode avaliar os deslocamentos das massas, rotações, forças atuantes em cada uma das rodas, velocidades e acelerações das massas, etc.

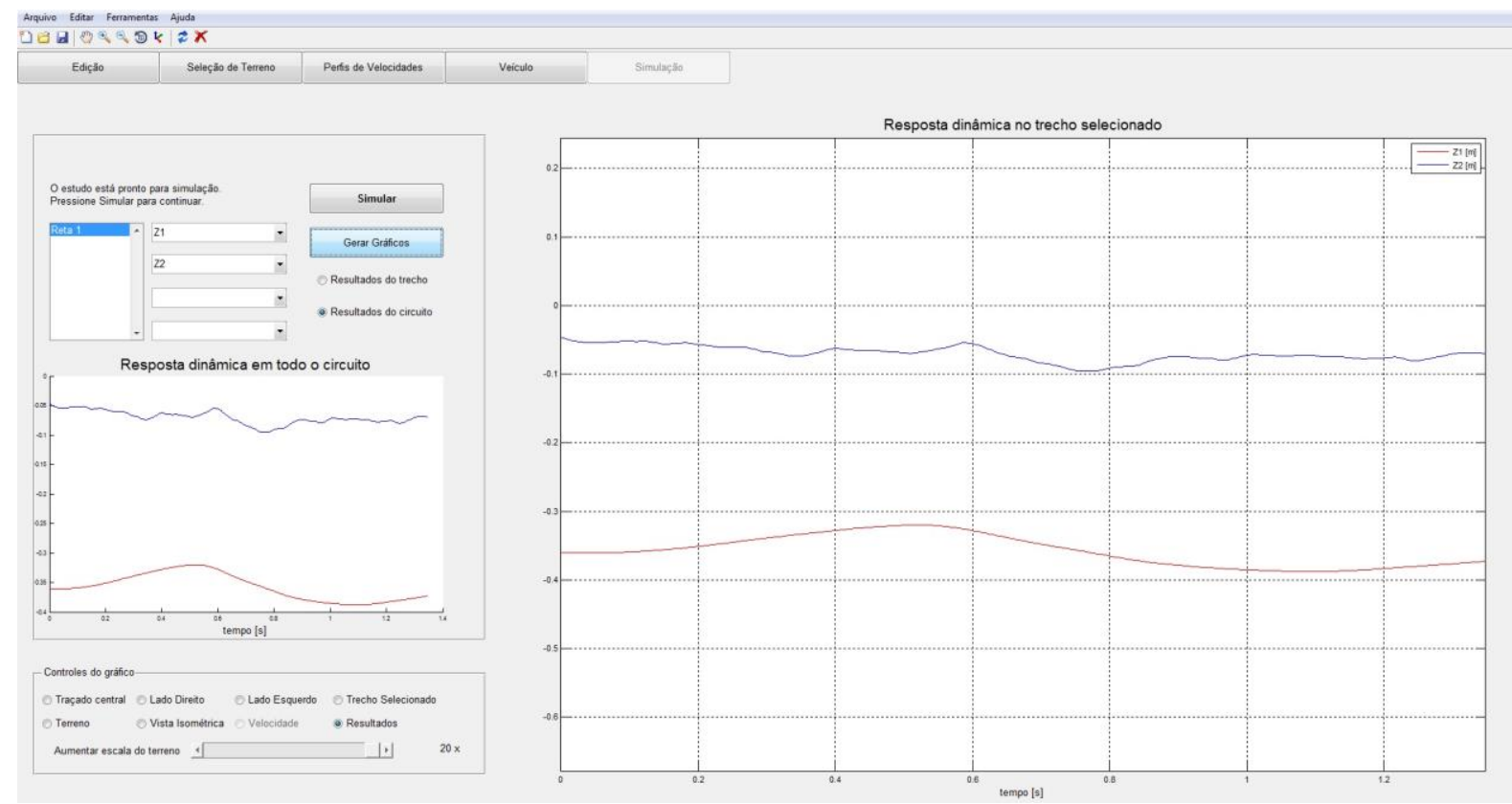

Figura 7. Janela de resultados da simulação. 


\section{CONCLUSÃO}

O programa desenvolvido tem se mostrado eficiente na criação de circuitos de testes com geometrias variadas e eficiente na geração e organização das variáveis necessárias para a análise dinâmica realizada pelo algoritmo de simulação. Além disso, a facilidade no acesso aos parâmetros da simulação permite a rápida avaliação dos impactos gerados na estrutura com a alteração das características do veículo, diminuindo assim o tempo e os custos durante o projeto da estrutura.

Assim, o programa poderá ser utilizado como uma plataforma de auxílio na simulação e análise estrutural de veículos, em alternativa aos poucos programas comerciais confiáveis existentes.

\section{REFERÊNCIAS}

[1] Jazar, R. N. (2008). Vehicle Dynamics Theory and Application, Springer, New York, USA.

[2] T.P. Chang, Dynamic Response of Space Structures Under Randon Excitation, Computers \& Structures, 48, 575-582, 1993.

[3] R.R. Craig Jr., Structural Dynamics, John Wiley \& Sons, 1981.

[4] R.D. Cook, D.S,. Malkus, M.E. Plesha, Concepts and Applications of Finite Element Analysis, John Wiley \& Sons, 3rd ed., 1988.

[5] K.J. Bathe, Finite Element Procedures, Prentice-Hall, 1996.

[6] E. Rosa, M.A. Luersen, R.J. Marczak, Análise de Resistência Mecânica do Chassi do Caminhão Agrale D1800, Publicação interna, EMC-UFRGS, 1993.

[7] L. Meirovitch, Elements of Vibration Analysis, McGraw-Hill, 1975.

[8] Dodds, C.J. e Robson, J.D., The description of Road Surface Roughness, Journal of Sound and Vibration 31 (2), pp. 175-183, 1973.

[9] Gillespie, T.D., Fundamentals of Vehicle Dynamics, Society of Automotive Engineers, Warrendable, 1992.

[10] Santos, Daiane Pioli dos, R. J. Marczak, Algoritmo para Geração e Análise de Curvas PSD de Pavimentos Rodoviários, Salão de Iniciação Científica, UFRGS, 2013. Disponível em http://hdl.handle.net/10183/91748. Acesso em 21/05/2015. 